\title{
Disputas en la producción del ordenamiento territorial de bosques nativos ("Ley de Bosques") en el delta bonaerense del río Paraná
}

\section{Patricio Hernán Straccia ${ }^{1}$}

\author{
1 CONICET, Buenos Aires, Argentina. \\ Universidad de Buenos Aires, Departamento de Economía, Desarrollo y Planeamiento Agrícola, Cátedra de \\ Extensión y Sociología Rurales, Buenos Aires, Argentina. \\ (iD) http://orcid.org/oooo-0002-4039-8717 \\ Correo electrónico: straccia@agro.uba.ar
}

Recibido:

28 de noviembre de 2019 Aceptado:

26 de marzo de 2020

doi: 10.34096/runa.v42i1.9954

\section{Resumen}

El objetivo del artículo es analizar la articulación del colectivo de identificación "isleños" en el proceso de producción del ordenamiento territorial de los bosques nativos (OTBN) del delta bonaerense del río Paraná en el período 2009-2014, realizado en el marco de la "Ley de Bosques". Para ello se produjeron datos primarios a partir de técnicas etnográficas, complementados con análisis documental de fuentes secundarias. Se propone una periodización en tres etapas: las disputas en la producción de la primera propuesta de OTBN (2009-2011), la realización de un taller en la zona (octubre de 2011) y la producción de la segunda (y definitiva) propuesta de OTBN para la Región Delta (2012-2014). Finalmente, mostramos los usos políticos de la identidad "isleña" en este proceso y reflexionamos sobre la importancia de los estudios etnográficos en la producción de políticas ambientales, incluso en casos en que el potencial conflicto es resuelto por medio de carriles no confrontativos.

\section{Conflicts in the production of the territorial planning of native forests ("Forest Law") in the Buenos Aires delta of the Paraná River}

\begin{abstract}
The aim of the article is to analyze the articulation of the identification group "isleños" ("islanders") in the production process of the territorial planning of native forests (TPNF) in the Buenos Aires delta of the Paraná River in the period 2009-2014, carried out within the framework of the "Forest Law". To do so, primary data were produced through ethnographic techniques, complemented by documentary analysis of secondary sources. The article analyzes the struggles in the production of the first TPNF proposal (2009-2011), a Workshop held in
\end{abstract}

\section{Palabras clave}

Políticas ambientales; “Ley de Bosques"; OTBN; Delta del río Paraná; Identidadl 
the Buenos Aires Delta with the presence of local agents (October 2011) and the struggles in the production of the second (and final) TPNF proposal for the Delta Region (2012-2014). Finally, we highlight the political uses of local identity and reflect on the relevance of ethnographic studies in the production of environmental policies, even in cases like this where the potential conflict is solved through non-confrontational lanes.

\section{Disputas na produção do planejamento territorial das flores- tas nativas ("Lei das Florestas") no delta de Buenos Aires do rio Paraná}

\section{Resumo}

Palavras-chave

Políticas ambientais; "Lei das Florestas"; Planejamento Territorial; Delta do rio Paraná; identidade
O objetivo deste artigo é analisar a articulação do grupo de identificação "isleños" ("ilhéus") no processo de produção do planejamento territorial das florestas nativas (PTFN) do delta bonaerense do rio Paraná no período 20092014, realizado no âmbito da "Lei das Florestas". Para isso, os dados primários foram produzidos por meio de técnicas etnográficas, complementadas pela análise documental de fontes secundárias. $\mathrm{O}$ artigo propõe uma periodização em três etapas: a produção da primeira proposta da PTFN e as disputas em torno dela (2009-2011), a realização de um Workshop realizado no setor de ilhas (outubro de 2011) e a produção de a segunda (e final) proposta da PTFN para a região do Delta (2012-2014). Finalmente, mostramos os usos políticos da identidade nesse processo e refletimos sobre a importância dos estudos etnográficos na produção de políticas ambientais, mesmo nos casos em que o conflito potencial é resolvido por vias sem confronto.

\section{Introducción}

El objetivo de este artículo es analizar la articulación del colectivo de identificación "isleños" en el proceso de producción del ordenamiento territorial de los bosques nativos del delta bonaerense del río Paraná en el período 2009-2014. Dicho ordenamiento fue realizado en el marco de la "Ley de Bosques", una política pública en materia ambiental que regula las formas de uso y apropiación de estos ecosistemas en Buenos Aires (Argentina).

En la actualidad, existe consenso en que los estudios sobre la producción de las políticas deben evitar la reificación del Estado (Abrams, 1988). Desde el campo de la antropología política, múltiples autores señalan que las políticas públicas son un campo de lucha entre distintos agentes y que debe considerarse la singularidad de los contextos sociohistóricos en los cuales se desarrollan sus procesos (Shore y Wright, 1997; Wedel, Shore, Feldman y Lathrop, 2005; Shore, 2010). En este campo, se ha propuesto hacer una antropología de la política que permita dotar de contenido(s) a abstracciones como política o Estado y trabajar sobre sus aplicaciones en los márgenes (Balbi y Boivin, 2008; Das y Poole, 2008). Se trata, además, de producir conocimiento antropológico crítico que permita contribuir a los procesos de producción e implementación de las políticas (Feito, 2005). 
La importancia de analizar las disputas en los procesos de producción de las políticas ambientales fue señalada por diversos autores (Melé, 2003; West, Igoe y Brockington, 2006; Piermattei, 2013). En muchas ocasiones, quienes promueven políticas de protección de la naturaleza responsabilizan a los habitantes locales por el subdesarrollo y la degradación ecológica (Nygren, 1999). Esto no quiere decir, sin embargo, que ellos necesariamente acepten tales acusaciones pasivamente ni que sean meras víctimas de las intervenciones externas: esto constituiría sencillamente una deformación romántica (Brosius, 1997). Por el contrario, los lugareños con frecuencia las cuestionan y reivindican sus opiniones sobre el uso más apropiado del lugar en el que viven (Bryant y Bailey, 1997; Bryant, 2000; Sundberg, 2004). En el marco de estas disputas, los estudios etnográficos sobre negociaciones, confrontaciones y resistencias dan cuenta de las formas en que se expresa la agencia de los habitantes locales (Brosius, 1997; Ferrero, 2005; Blaser, 2009). Estos estudios también muestran que la cuestión ambiental es construida en ciertos términos por los agentes hegemónicos pero, en muchas ocasiones, es recreada en esos mismos términos por los subalternos (Brosius, 1999). Así, la antropología del ambientalismo y la antropología para el ambientalismo evidencian las formas en que lo ambiental es construido, negociado y resignificado en las disputas por sus formas de uso y apropiación (Straccia y Pizarro, 2019).

En estos procesos de lucha, uno de los elementos que pueden ser movilizados por ciertos agentes es la adscripción identitaria (Alonso y Costa, 2002; Isla, 2003; Pizarro, 2006; Espósito, 2012). Los procesos de identificación son dinámicos y se producen en relación con una alteridad, de modo que la construcción del 'nosotros' supone también un 'otros constitutivo' (Hall, 2003). De este modo, la movilización de la identificación colectiva podría ser utilizada para definir quiénes son considerados legítimos para participar en la definición del problema y/o en la proposición de soluciones y quiénes no, lo cual favorecería procesos de inclusión de ciertos agentes y exclusión de otros (Opotow y Weiss, 2000).

Para el caso del Delta bonaerense del río Paraná (Argentina), un conjunto de islas que abarcan una superficie de aproximadamente 240.000 hectáreas, las formas de articulación del colectivo de identificación "isleños" fue analizada con anterioridad en el marco de otras disputas ambientales (Straccia, Monkes y Cowan Ros, 2019). Este artículo complementa dichos estudios haciendo énfasis en el caso específico de la producción del ordenamiento territorial de los bosques nativos en el marco de la "Ley de Bosques".

Las investigaciones de nuestro equipo se desarrollan en la Zona Núcleo Forestal, un área del delta bonaerense de aproximadamente 80.000 hectáreas sobre la cual tienen jurisdicción los partidos de Campana y San Fernando (figura 1), así denominada por tratarse de la zona con mayor productividad forestal y silvopastoril en la región (Moreira, 2018). Por otra parte, desde mediados de la década del noventa, un grupo de agentes definidos localmente como "ambientalistas" (Pizarro y Straccia, 2018) alertan sobre el impacto que tendrían las prácticas asociadas a estas actividades productivas y promueven la adopción de medidas proteccionistas con el fin de asegurar la continuidad en la provisión de bienes y servicios ecosistémicos (Blanco y Méndez, 2010). Sin embargo, sus propuestas han generado resistencias por parte de los productores y pobladores de la Zona Núcleo Forestal del Delta del Paraná, de modo tal que se ha configurado un campo de lucha en torno a la definición de las formas de uso y apropiación del ambiente en la región (Pizarro y Straccia, 2018). 
Figura 1. El delta del río Paraná: ubicación regional, secciones principales y ubicación de la Zona Núcleo Forestal. Fuente: Elaboración propia, adaptado a partir de Quintana y Bó (2011)

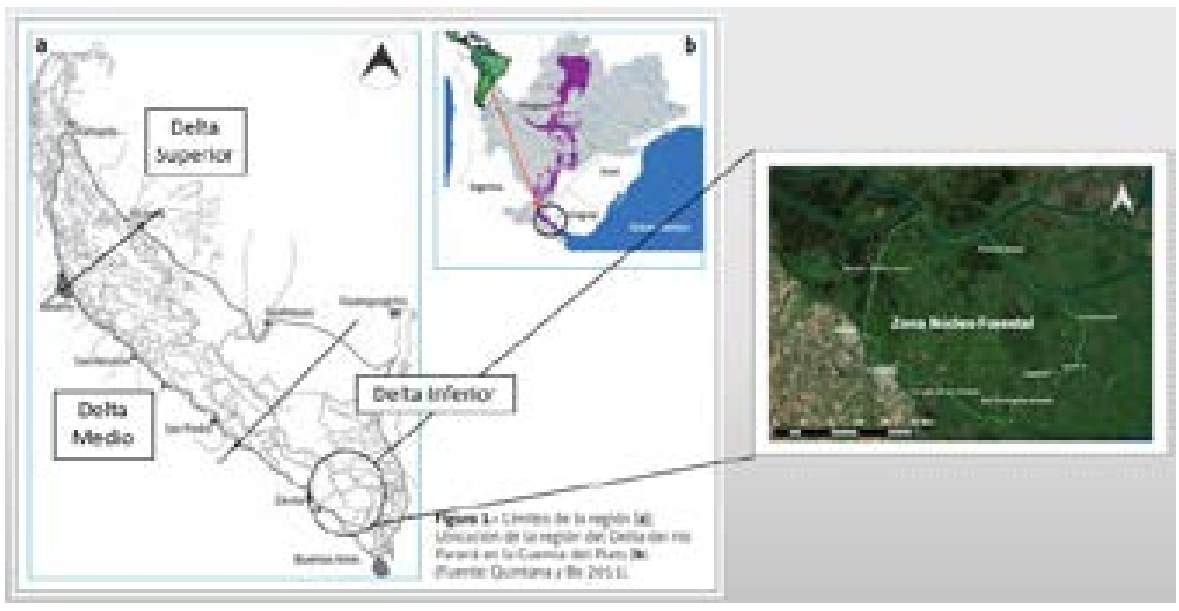

\section{Metodología}

La presente investigación es de tipo cualitativa y los datos primarios fueron producidos desde un enfoque etnográfico (Taylor y Bogdan, 1996; Guber, 2001; Hammersley y Atkinson, 2007), a fin de analizar las formas de articulación del colectivo de identificación "isleños" en el proceso bajo estudio. Este enfoque es de utilidad para estudiar las disputas en torno a la cuestión ambiental (Foladori y Taks, 2004) y requiere ubicarse en sus intersticios, analizar las relaciones entre los agentes sociales, y también construir un espacio propio (Little, 2007). Se trata también de implicarse y de reconocer cómo somos construidos en los espacio-tiempos de otros (Althabe y Hernández, 2004), en una investigación comprometida pero no siempre exenta de contradicciones (Hale, 2006).

Desde el año 2012 hemos realizado entrevistas semiestructuradas con técnicos y funcionarios de instituciones ambientales, de desarrollo rural y de promoción de la forestación en el delta bonaerense, así como con representantes de asociaciones de productores familiares empresariales y empresas agroindustriales de la región. También realizamos entrevistas en profundidad con productores y pobladores, lo que nos permitió recorrer sus campos y conocer sus historias, sus formas de vida y las situaciones que consideran amenazantes para su permanencia en la zona. En todos los casos, también llevamos adelante entrevistas informales, en tanto encuentros no programados con grados mínimos de formalización y estandarización (Penalva Verdú, Alaminos Chica, Francés García y Santacreu Fernández, 2015). El muestreo fue cualitativo no probabilístico, combinando un muestreo de oportunidad a partir de la técnica de la bola de nieve con un muestreo evaluado (Guber, 2001).

Las entrevistas se complementaron con instancias de observación participante en diversos eventos ocurridos durante el período 2012 y 2018, entre los que se incluyen audiencias públicas, audiencias abiertas, festividades locales y encuentros organizados por diferentes instituciones estatales, entre otros. Los registros construidos a partir de estas instancias también fueron incorporados al análisis a fin de comprender los puntos de vista y las estrategias desarrolladas por los diferentes agentes sociales (Tsing, 2005; Skill, 2010), aunque sin desconocer que, como señala Balbi (2012), aquello que llamamos 'perspectivas nativas' en la práctica etnográfica es, en realidad, una construcción analítica de los investigadores. 
Finalmente, también se realizó un análisis de contenido de diversas fuentes secundarias, entre las que se incluyen el texto de la ley bajo estudio, actas de audiencias públicas, noticias periodísticas y documentos elaborados por las instituciones estatales en el proceso de institucionalización de la "Ley de Bosques". Todos los registros producidos fueron posteriormente codificados y analizados a través del programa Atlas.Ti 6.2 (Penalva Verdú et al., 2015).

\section{El colectivo "isleño": de los "pioneros" a la actualidad}

En el delta bonaerense del río Paraná, el Estado nacional favoreció la colonización de las islas y promovió sostenidamente procesos migratorios que facilitaron la llegada y el asentamiento de vascos, portugueses e italianos, entre otros inmigrantes europeos, desde mediados del siglo XIX (Galafassi, 2004). Hacia mediados del siglo XX, se estima que no menos de 25.000 personas habitaban en "la isla". ${ }^{1}$ La producción frutícola y hortícola eran las actividades dominantes, y sus productos se destinaban al autoconsumo y a los mercados de áreas urbanas cercanas (Galafassi, 2004, 2005).

A lo largo de sucesivas generaciones, las familias pioneras domesticaron este espacio agreste y lo convirtieron en su lugar (Escobar, 2000). Los pobladores locales recuerdan la gesta de sus antepasados (Astelarra, 2018), quienes lograron "convertir a la isla en algo lindo" "a fuerza de machete", "con el agua hasta la cintura" (Pizarro, Ciccale Smit y Moreira, 2018), y señalan que son ellos quienes convirtieron a "la isla" en un lugar habitable a través de procesos que sintetizan con la expresión "nosotros creamos el Delta" (Pizarro, 2019).

Sin embargo, las "mareas" de 1959 y de 1982/1983 -que cubrieron completamente de agua las islas y cuyos impactos están grabados en la memoria colectiva isleña (Pizarro et al., 2018, Astelarra, 2018)-, el incremento de los costos de transporte, la ocurrencia de heladas y el desarrollo de regiones productoras más competitivas afectaron la actividad frutihortícola (Galafassi, 2005). Por otra parte, diversas políticas nacionales favorecieron el crecimiento de la actividad forestal en la región, y la mayor parte del área actualmente denominada Zona Núcleo Forestal comprende establecimientos forestales, silvopastoriles y/o ganaderos con distintos niveles de sistematización (Galafassi, 2005; Moreira, 2018).

Al mismo tiempo, en la segunda mitad del siglo XX se produjo un progresivo despoblamiento de las islas: según el censo del año 2010, en el delta bonaerense había poco más de 10.000 habitantes (Olemberg, 2015). En este período también se produjo una diferenciación y movilización socioeconómica que dio lugar a la actual conformación de la estructura social agraria: según Pizarro (2016), en la Zona Núcleo Forestal está conformada por pequeños productores familiares, productores familiares capitalizados, productores familiares empresariales y empresas forestoindustriales. Las familias históricas de la región, cuyos antepasados también son "nacidos y criados" en "la isla" (dimensión central en las subjetividades de quienes se definen como "isleños"), están comprendidas en los primeros tres tipos de productores. La tipología propuesta permite capturar las diferencias socioeconómicas actuales entre dichas familias, sin perder de vista su historia colectiva común.

Los pequeños productores familiares poseen explotaciones cuyos tamaños ( 30 hectáreas) se encuentran debajo de la unidad económica forestal. Su principal actividad es la forestación mediante mano de obra familiar, complementada
1. Utilizamos comillas dobles para referir a categorías nativas emergentes y expresiones textuales de nuestros entrevistados en el transcurso del trabajo de campo. 
con otras actividades secundarias (turismo o producción hortícola, entre otras). Los productores familiares capitalizados (con superficies promedio de $\sim 500$ hectáreas) llevan adelante producción forestal y ganadera mediante mano de obra familiar complementada con mano de obra extrafamiliar. Cuentan, en algunos casos, con sus propios aserraderos. Los productores familiares empresariales, por su parte, poseen explotaciones forestales y silvopastoriles que superan largamente la unidad económica. Son propietarios de empresas familiares de origen local: la gestión es mayormente familiar pero el trabajo en las explotaciones es realizado por mano de obra extrafamiliar, y han dado un salto organizacional pasando de una lógica familiar a una lógica empresarial. Finalmente, las empresas forestoindustriales son propiedad de grupos económicos extralocales y cuentan con grandes superficies forestadas. Presentan una alta integración vertical y, a diferencia de las empresas familiares, han tenido una lógica empresarial desde sus orígenes.

En otras regiones del delta bonaerense, la estructura social agraria es diferente. Para las zonas de San Fernando con actividad mimbrera, Olemberg (2015) plantea la existencia de empresarios del mimbre y de mimbreros familiares, según las diferencias en las lógicas de producción. Para el caso de Tigre, Astelarra y Domínguez (2015) caracterizaron a los junqueros, en tanto sujetos emergentes en un territorio amenazado por el avance de los megaemprendimientos inmobiliarios. Sin embargo, para nuestro análisis retomaremos la clasificación de Pizarro (2016), dado que, en el proceso bajo estudio, fueron los agentes sociales vinculados con la actividad forestal y silvopastoril quienes participaron de forma casi exclusiva en estas instancias.

A lo largo de nuestro trabajo de campo hemos detectado que las demandas de los pobladores locales se repiten casi textualmente año tras año, independientemente de cuál sea la coalición gobernante tanto a nivel provincial como nacional: para muchos, "la isla está olvidada" "porque somos pocos votos". Incluso la mayor parte de las organizaciones locales existentes, fundadas en distintas décadas del siglo $\mathrm{XX}$, tuvieron (y tienen) como fin la provisión de servicios específicos para la población local.

\section{Las leyes de presupuestos mínimos de protección ambiental}

En Argentina, la reforma de 1994 consagró el derecho a un ambiente sano en el art. $41 \mathrm{CN}$. Según lo establece dicho artículo, uno de los principales instrumentos para favorecer la conservación del ambiente son las leyes de presupuestos mínimos de protección ambiental. Así, corresponde al Estado nacional dictar las normas que contengan los estándares básicos, de modo de generar una tutela ambiental uniforme para todo el país que imponga las condiciones necesarias para asegurar la protección ambiental (Esain, 2004). Los Estados provinciales, por su parte, deben dictar las normas necesarias para complementarlas.

La Ley de Presupuestos Mínimos de Protección Ambiental de los Bosques Nativos (LN 26.331) fue sancionada por el Congreso nacional a fines del año 2007. La ley establece la obligatoriedad para cada provincia de producir un ordenamiento territorial de sus bosques nativos (de aquí en adelante, OTBN). Es decir, cada provincia debía, de modo inicial, inventariar sus bosques nativos, y posteriormente categorizarlos de acuerdo con los lineamientos definidos por la ley nacional. A cada área relevada debía asignársele alguno de los tres niveles de conservación posibles: zonas rojas (de alto valor de conservación 
e imposibilidad de transformación), zonas amarillas (de mediano valor de conservación y aprovechables sosteniblemente) o zonas verdes (de bajo valor de conservación y con pocas restricciones para el desarrollo de actividades productivas). El OTBN producido, finalmente, debía ser sancionado mediante una ley provincial. En este artículo, utilizamos la categoría "Ley de Bosques" para referir a la norma complementaria que la provincia de Buenos Aires debía sancionar para adherir a la ley nacional, y que comprendería el OTBN en cuestión.

Desde las ciencias sociales se han analizado los conflictos en la producción del OTBN en distintas provincias (Silvetti, Soto, Cáceres y Cabrol, 2013; Schmidt, 2014; Koberwein, 2018; entre muchos otros), aunque no el caso específico de Buenos Aires. Además, los informes de la autoridad nacional de aplicación oportunamente producidos sobre el estado de implementación de la ley nacional tampoco incluyen a esta provincia, porque esta aún no había sancionado la ley complementaria correspondiente (MAyDS, 2016).

\section{La producción del ordenamiento territorial de los bosques nativos del delta bonaerense del río Paraná (2009-2014)}

De acuerdo con lo establecido por la Ley Provincial 13.757, el Organismo Provincial para el Desarrollo Sostenible (en adelante, OPDS), en tanto máxima autoridad provincial en materia ambiental, sería el encargado de realizar el OTBN. Para llevar adelante esta tarea, el OPDS decidió zonificar la provincia en cuatro regiones: Talares de Barranca y Delta; Bosque Ribereño; Talares del Este; y Cardenal y Monte (OPDS, 2013). Dado que el ordenamiento se realizó por separado para cada una de ellas, aquí nos focalizamos en estudiar el proceso desarrollado en la primera región, Talares de Barranca y Delta, a fin de analizar la articulación del colectivo de identificación "isleños".

A fines de 2008, un evento externo, un shock en los términos de Sabatier (1991), modificó sustantivamente la estructura de este (incipiente) campo de lucha. La Ley 25.080 de Promoción Forestal había sido sancionada en 1998 y otorgaba una serie de beneficios que fueron centrales para contribuir a la consolidación de esa actividad en el Delta del Paraná (Fernández, 2016). En el año 2008, fue prorrogada por medio de la LN 26.432. Sin embargo, la prórroga incluyó un artículo que especificaba que solo se promovería la implantación de bosques cultivados en zonas que no estuvieran afectadas por el OTBN realizado en el marco de la Ley 26.331 de Protección Ambiental de los Bosques Nativos. Así, se buscaba evitar que el incremento de la superficie de bosque implantado se lograra a expensas de avanzar sobre los bosques nativos remanentes.

Como resultado, los productores forestales no podrían acceder a los beneficios de la Ley de Promoción Forestal hasta tanto la provincia de Buenos Aires no sancionara su "Ley de Bosques". Y, por lo tanto, los agentes sociales vinculados con la forestación en el delta bonaerense se convirtieron en demandantes primarios de la construcción de un OTBN que les permitiera continuar con dicha actividad. Así, no solo los productores forestales lo demandaban, sino también los técnicos de las instituciones estatales de desarrollo rural y de promoción de la forestación. En otras palabras, esta confrontación no podía ser interpretada en los términos "isleños" vs Estado ni en términos agentes estatales vs agentes no estatales, sino en términos de dos grandes grupos (agentes asociados a la conservación vs. agentes asociados a la protección), similares a las coaliciones caracterizadas por Gutiérrez (2017) para otras regiones del país. 
Figura 2. Etapas del proceso de institucionalización de la "Ley de Bosques" en la Región "Talares de Barranca y Delta". Fuente: Elaboración propia.
El proceso de institucionalización de la "Ley de Bosques"

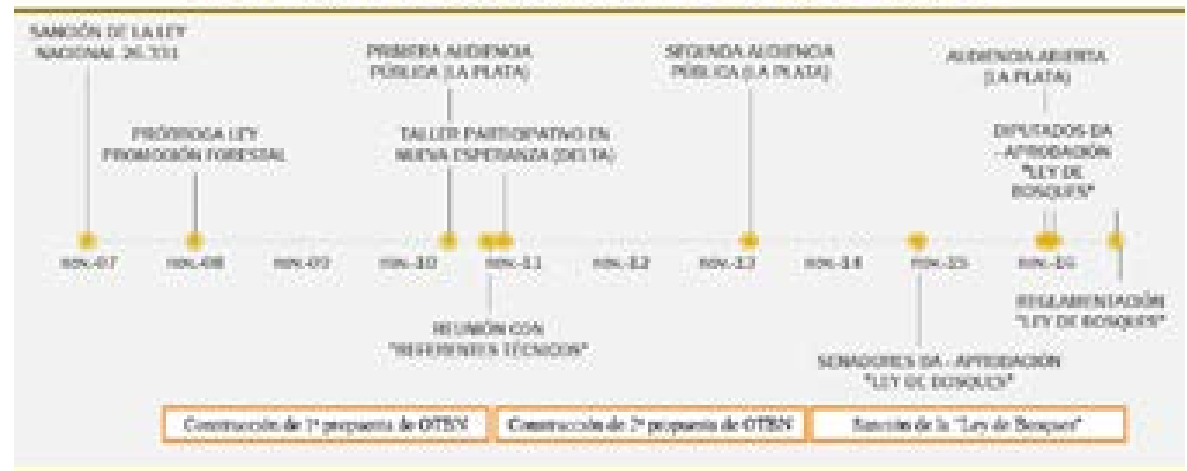

Para alcanzar nuestro objetivo, separaremos el análisis en tres partes (figura 2). En primer lugar, daremos cuenta de la producción de la primera propuesta de OTBN y las disputas en torno a ella (2009-2011). Luego, nos focalizaremos en analizar lo acaecido en un taller realizado en octubre de 2011 en el sector de islas y que algunos de los entrevistados señalaron como un hito en el proceso de producción de la política. Finalmente, daremos cuenta de los modos en que se produjo la propuesta definitiva de OTBN para la Región Delta (2012-2014). Así, el análisis diacrónico nos permitirá aprehender la dimensión contingente del proceso político, y focalizar tanto en las correlaciones de fuerzas existentes entre los agentes en un tiempo y espacio dado como en su carácter dinámico a lo largo del tiempo (Koopmans y Statham, 2000).

\section{"El inventario era una locura, una locura total". La primera propuesta de OTBN del delta bonaerense del Paraná (2009-2011)}

Al ser entrevistados en sus oficinas en el año 2017, los técnicos de la autoridad provincial de aplicación argumentaron que se vieron forzados a realizar el OTBN sin los recursos necesarios. Esto mismo fue señalado por los técnicos de otras instituciones estatales, quienes en conversaciones informales indicaron que la falta de personal y la escasa disponibilidad de movilidad impedían que pudieran realizar todas las actividades necesarias para la construcción del OTBN (Registro de campo, técnicos de instituciones de desarrollo y de promoción forestal, Buenos Aires, febrero de 2017). Sin embargo, pese a esas limitaciones, los entrevistados se mostraron "muy orgullosos" de haber realizado un trabajo del cual se sentían satisfechos, hecho "con esfuerzo, voluntad y sin fondos", "respetando la metodología que proponía la autoridad nacional de aplicación [...] y aprendiendo sobre la marcha" (Juan María, Jorge, Agostina, Lara y Ana, entrevista grupal, abril de 2017).

En un primer momento llevaron adelante procesos de articulación con referentes técnicos, quienes brindarían las herramientas necesarias para la construcción preliminar de un primer OTBN. Para la región Delta, los primeros referentes técnicos con los que articularon fue con científicos especializados en ecología de humedales que desarrollan sus trabajos desde perspectivas biológico-ecológicas, los cuales son definidos como "ambientalistas" por los lugareños (Pizarro y Straccia, 2018). Los insumos principales utilizados fueron dos: una tesis de grado en la que se había realizado un inventario preliminar de los bosques nativos de la región a partir de la interpretación de secuencias de imágenes satelitales, y un estudio sobre parches relictuales de Monte Blanco en la zona. 
A partir de estas primeras articulaciones, en abril de 2011, la autoridad de aplicación llevó adelante la primera audiencia pública en el marco de la "Ley de Bosques" (OPDS, 2011a). Esta audiencia, de carácter provincial, estuvo signada por el intento de ciertas asambleas vecinales de visibilizar un conflicto que se había iniciado en el año 2008 en los partidos de Quilmes y Avellaneda (Calefato, 2018). Allí, el avance de un emprendimiento inmobiliario desarrollado por Techint atentaba contra los bosques nativos ribereños, y era resistido por quienes sostenían que constituían una degradación y privatización de estos espacios comunes (Santy, 2014).

La presencia de oradores vinculados con la Región Delta, en cambio, fue muy limitada; apenas tres asistieron y tomaron la palabra: dos de ellos vinculados a la forestoindustria, y el tercero, en calidad de representante municipal. Los tres, sin embargo, coincidieron en señalar la especificidad del Delta respecto de las otras regiones de la provincia, y plantearon la necesidad de realizar encuentros específicos para la zona en los que participaran agentes locales. De esta forma, los oradores desarrollaron estrategias con el fin de incidir en el proceso político, participando en las instancias disponibles pero a la vez intentando construir otras nuevas. Y lo hicieron por medio de argumentos que reproducían elementos de sentido del discurso ambiental y que no cuestionaban las premisas básicas de la "Ley de Bosques" (existen áreas de bosques nativos remanentes, y éstas deben estar sujetas a algún tipo de protección), pero que al mismo tiempo buscaban señalar la singularidad de la región, en tanto "polo forestal" "desde hace doscientos años" (OPDS, 2011a).

Algunos meses más tarde, el OPDS presentó la primera propuesta formal de OTBN para la región Delta del Paraná (figura 3), la cual retomó tanto los estudios ecológicos mencionados previamente como los ordenamientos municipales preexistentes. Así, en este inventario, la porción insular correspondiente a San Fernando (que había sido categorizada como Reserva de Biosfera MaBUNESCO algunos años atrás) era considerada en su totalidad como bosque nativo y se proponía replicar la zonificación propuesta al momento de su

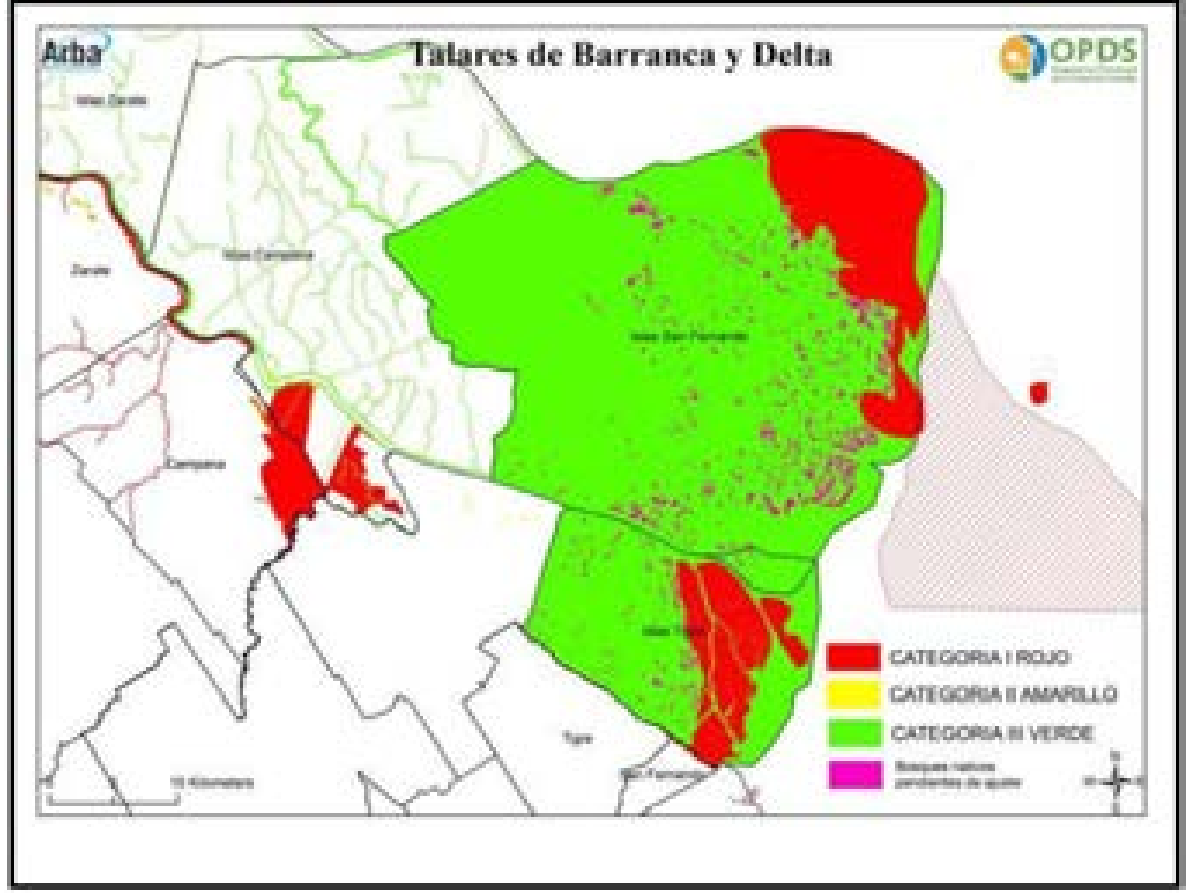

Figura 3. Primera propuesta de ordenamiento territorial de los bosques nativos de la región "Talares de Barranca y Delta". Fuente: OPDS (2011b). 
constitución. En Tigre se observaba una situación similar: la totalidad del área insular era inventariada como bosque nativo y se replicaba la zonificación del Régimen de Protección Cautelar Ambiental sancionado por Ordenanza Municipal 3178/11. En Campana, por su parte, los albardones -espacios de las islas que geomorfológicamente se encuentran a mayor altura y han sido modificados antrópicamente desde el siglo XIX (Galafassi, 2004)- eran relevados como bosques nativos de bajo nivel de conservación en los que se permitiría el aprovechamiento sustentable.

Los productores forestales del Delta del Paraná se manifestaron abiertamente en contra de esta primera propuesta de ordenamiento. Desde sus puntos de vista, se inventariaban como 'bosque nativo' áreas en las cuales ellos llevaban adelante producción forestal y ganadera desde hacía décadas, y eso podía restringirles la posibilidad de continuar con sus prácticas productivas y de vida. Y es que, como fuera previamente señalado, la potencial consecuencia de este ordenamiento, si era sancionado, era que les podría impedir a los productores forestales acceder a los beneficios de la Ley 26.432 de Promoción Forestal. Sin embargo, es necesario tener en cuenta que no todos tenían la misma capacidad de acceso a dichos beneficios: de acuerdo con Fernández (2016), hasta el año 2009, los pequeños productores familiares habían recibido subsidios por el 15\% de la superficie total subsidiada en la región, mientras que los productores familiares empresariales habían recibido subsidios por el $59 \%$ de la superficie total subsidiada.

Esta posición contraria a la propuesta de ordenamiento, y con los mismos argumentos, era compartida por los técnicos de las agencias estatales vinculadas al desarrollo rural y la promoción de la forestación. En palabras de uno de ellos técnicos de una institución estatal de desarrollo rural, el primer inventario propuesto "era una locura, una locura total" (Guillermo, entrevista en noviembre de 2016). Y es que la confrontación territorial era planteada en función de quiénes estaban legitimados para participar en este proceso: los productores forestales y silvopastoriles, así como los técnicos de las distintas agencias, coincidían en que este debía ser llevado adelante a partir de los aportes de quienes viven y trabajan cotidianamente en "la isla".

\section{"¿Habrá cuarta generación o nos iremos?". Un taller en el delta bonaerense del Paraná (2011)}

En octubre de 2011 se realizó un taller participativo en el delta del Paraná, donde representantes de las autoridades nacionales y provinciales de aplicación expusieron la primera propuesta de OTBN para la región y recibieron las devoluciones de los agentes locales. Los productores forestales más capitalizados y los técnicos de las instituciones estatales de desarrollo rural y de promoción de la forestación asistieron al taller y coincidieron en señalarlo como un hito en el proceso. ${ }^{2}$ Una dimensión central fue el lugar donde se realizó:

se hizo [...] en el medio de la isla. Entonces para llegar a ese taller tenías que cruzar el Paraná y llegar a un montón de plantaciones, de caminos, de diques y demás, entonces así les podíamos mostrar a todos los asistentes qué era lo que habían señalado como bosque nativo. De hecho, hacerlo en el Delta hizo que pudieran asistir los productores, que en general no salen de la isla. (Sergio, funcionario de una institución estatal de promoción de la forestación, entrevista en diciembre de 2016)
Sin embargo, los product familiares con menores grados referencia a esta instancia de participación. A partir de estas observaciones, debemos recordar que los hitos no son, sino que son construidos como tales por y para ciertos agentes (Laclau y Mouffe, 1987). En este caso, por los productores forestales con mayor grado de capitalización y por los agentes estatales vinculados a la actividad forestal y al desarrollo rural. 
Cabe señalar aquí que, siguiendo a Noel (2013), consideramos que quienes nos relataron fragmentos de lo ocurrido durante estos procesos evaluaron sus acciones de manera retrospectiva desde el presente de la enunciación. Y que en sus relatos los narradores manifiestan sus valoraciones sobre lo narrado, las que se anclan en la sedimentación de las experiencias pasadas. En este caso, el interlocutor refiere implícitamente a una apreciación que escuchamos reiteradas veces a lo largo de nuestro trabajo de campo y que los pobladores locales señalan recurrentemente: la ignorancia de quienes diseñan políticas "desde el escritorio", "sin conocer el territorio" (Roberto, dirigente de una asociación local, noviembre de 2013) y "sin saber de qué están hablando" (Carlos, representante de una asociación local, marzo de 2017).

Desde estas perspectivas, los "isleños" sostienen que las políticas públicas deberían definirse en función de lo planteado por quienes viven y trabajan allí. Así, valoran positivamente a los técnicos de las múltiples instituciones estatales que operan en territorio porque "conocen la isla", pero cuestionan abiertamente las propuestas de intervención que son construidas "desde afuera". Así, pues, las confrontaciones en torno a lo ambiental son definidas principalmente por medio de la dicotomía locales / no-locales (Straccia, 2019).

Para el caso bajo análisis, la afirmación de varios "isleños" de que serían ellos y los técnicos que trabajan en el territorio quienes estarían en condiciones de señalar dónde se encuentran las porciones remanentes de bosque nativo en el Delta del Paraná (y no quienes miran las cosas "desde el escritorio") permitía cuestionar el inventario realizado. Pero, a la vez, también negaba la legitimidad de los asesores "ambientalistas" y de los técnicos de la autoridad de aplicación para llevar adelante esta tarea, en tanto no-locales (Opotow y Weiss, 2000).

Por otra parte, el camino que atraviesa las islas y permite llegar al lugar donde se realizó el taller está rodeado por plantaciones de álamo con altos niveles de manejo. Así, mostrar "qué era lo que habían señalado como bosque nativo" permitía señalar que allí efectivamente no había bosques nativos y, simultáneamente, contribuir a reforzar la imagen de esta zona como un área forestal pujante que debía seguir recibiendo los beneficios otorgados por la Ley de Promoción Forestal.

Finalmente, como lo señalara nuestro interlocutor en la cita precedente, realizar el taller en "la isla" permitió la "afluencia de muchos productores isleños". Esta afluencia fue estimulada por los técnicos de las diversas instituciones estatales que operan en territorio. En ese encuentro, el técnico entrevistado indicó que "nosotros los azuzamos, les dijimos 'tienen que estar, tienen que estar', y estuvieron", y recordó que al encuentro "asistieron más de cien productores y habitantes del Delta" (Sergio, funcionario de una institución estatal de promoción de la forestación, entrevista en diciembre de 2016). Así, la referencia explícita a los "habitantes" del Delta supone una modificación de los términos de la disputa: se trata de trascender, cuanto menos discursivamente, la tensión entre un bloque proteccionista y un bloque productivista (y la reproducción económica de los "isleños", en tanto productores) para incorporar la tensión con la posibilidad misma de vivir en "la isla", en su lugar (es decir, la reproducción social de los "isleños", en tanto habitantes).

A partir de un análisis documental de las actas del taller (OPDS, 2011b), podemos señalar que el $50 \%$ de los presentes eran "productores y habitantes del Delta", esto es, "isleños". Sin embargo, la mayor parte de ellos eran específicamente productores forestales con alto nivel de capitalización. Esto 
podría deberse a que fueron ellos quienes se sintieron más interpelados por esta problemática, dado que, como hemos visto, eran quienes accedían con mayor facilidad a los subsidios otorgados por la Ley de Promoción Forestal. Los productores familiares menos capitalizados, en cambio, solían encontrar mayores dificultades para ello, y lo largo de nuestro trabajo de campo pudimos detectar que muchos no estaban presentando planes en el marco de la ley por diferentes dificultades con las que se habían encontrado. No solo eso sino que, además, muchos cuestionaban que desde el año 2009 habían presentado planes a instancias de las propias agencias estatales de promoción de la forestación pero luego no habían recibido los beneficios correspondientes. Por lo tanto, la limitada asistencia de pequeños productores familiares podría explicarse no por su exclusión deliberada por parte de ciertos agentes, sino por el escepticismo respecto de la aplicación de la Ley de Promoción Forestal entre este estrato de productores. Complementariamente, factores como las dificultades para movilizarse o la imposibilidad de disponer de una jornada completa de trabajo para este taller también pueden haber contribuido a esta asistencia limitada.

Según las actas del taller, los "isleños" que asistieron legitimaron sus posturas en contra de la propuesta de OTBN aludiendo a su condición de "sexta generación de isleños", "que saben vivir en la isla" (OPDS, 2011b), lo que configuró una vez más la confrontación en términos locales / no-locales. El colectivo "isleños", entonces, se articuló como un colectivo de identificación anclado en el sentido de pertenencia al lugar (Pizarro, 2006). Esto es, como una identidad territorial (Haesbaert, 1999).

Sin embargo, como señala Melucci (2004), los colectivos de identificación no son unidades monolíticas y su unidad empírica es un resultado, no un punto de partida. En otras palabras, la categoría "isleños" no hace referencia a un grupo social homogéneo al cual se le pueden asignar intereses unificados. Esto mismo fue señalado por uno de los técnicos de la autoridad de aplicación durante la entrevista realizada en 2017:

[los isleños] tienen claro cómo armar un frente cuando están en contra de una norma. Por ejemplo, en principio con el primer mapa de la ley de bosques o la ley de humedales, ellos forman un frente homogéneo. Pero sabemos que hay distintos intereses hacia adentro. (Juan María, Jorge, Agostina, Lara y Ana, entrevista grupal, abril de 2017)

En el taller, los “isleños" presentes afirmaron que el OTBN propuesto "ataca la vida de los pobladores del Delta", y que "se ponen trabas para desarrollar una zona de gran potencial productivo". Sin embargo, al mismo tiempo, señalaron el "pleno consenso en preservar los relictos de bosque nativo" del Delta del Paraná. De este modo, reproducían ciertos elementos de sentido del discurso ambientalista pero a la vez manifestaban su rechazo a quienes los señalaban como responsables de la degradación del Delta, dado que "cuatro o cinco generaciones [...] dan idea de sustentabilidad" (OPDS, 2011b).

Evidentemente, su principal preocupación tenía que ver con las implicancias que el ordenamiento propuesto supondría para la continuidad de la producción forestal y silvopastoril, dado que podía restringir las actividades productivas preexistentes en algunas de las áreas inventariadas como bosque nativo. Pero ellos argumentaban que esto implicaba más que una amenaza para la persistencia de la producción: también lo era para la persistencia de la vida en las islas. Y la identidad territorial "isleña" se ancla en la sedimentación de 
históricos procesos migratorios de expulsión, resultantes de las inclemencias climáticas pero también de las reconversiones productivas (Pizarro, 2019). Quizás ello permita comprender por qué otro de los "isleños" presentes, tal vez sintetizando la preocupación de muchos más, se preguntó: “¿habrá cuarta generación, o nos iremos?" (OPDS, 2011b).

\section{La construcción de una propuesta "consensuada" del OTBN del delta bonaerense del Paraná (2012-2014)}

En las instancias previas, tanto los "isleños" como los técnicos estatales vinculados con la actividad forestal manifestaron su disconformidad con la metodología utilizada para inventariar los bosques nativos. Como hemos visto, el asesoramiento de los referentes técnicos se había cimentado en la interpretación de secuencias de imágenes satelitales, y muchos de los asistentes al taller coincidieron en señalar la necesidad de "empezar con los pies sobre la tierra" (OPDS, 2011b). Más específicamente, cuestionaban que la fotointerpretación fuera válida en sí misma, e indicaban que primero debían realizarse recorridas al campo para verificar la (posible) existencia de bosques nativos y recién a continuación definir la categorización de los bosques relevados.

Sobre ese eje se produjo la articulación entre los técnicos de la autoridad de aplicación provincial, los productores forestales con niveles elevados de capitalización y los técnicos de las instituciones estatales vinculadas con la forestación. Y a partir de esta articulación, se construyó una segunda propuesta de OTBN para el delta bonaerense.

Según uno de nuestros interlocutores, esta articulación permitió que los técnicos de la autoridad de aplicación reconocieran "que realmente no había bosque

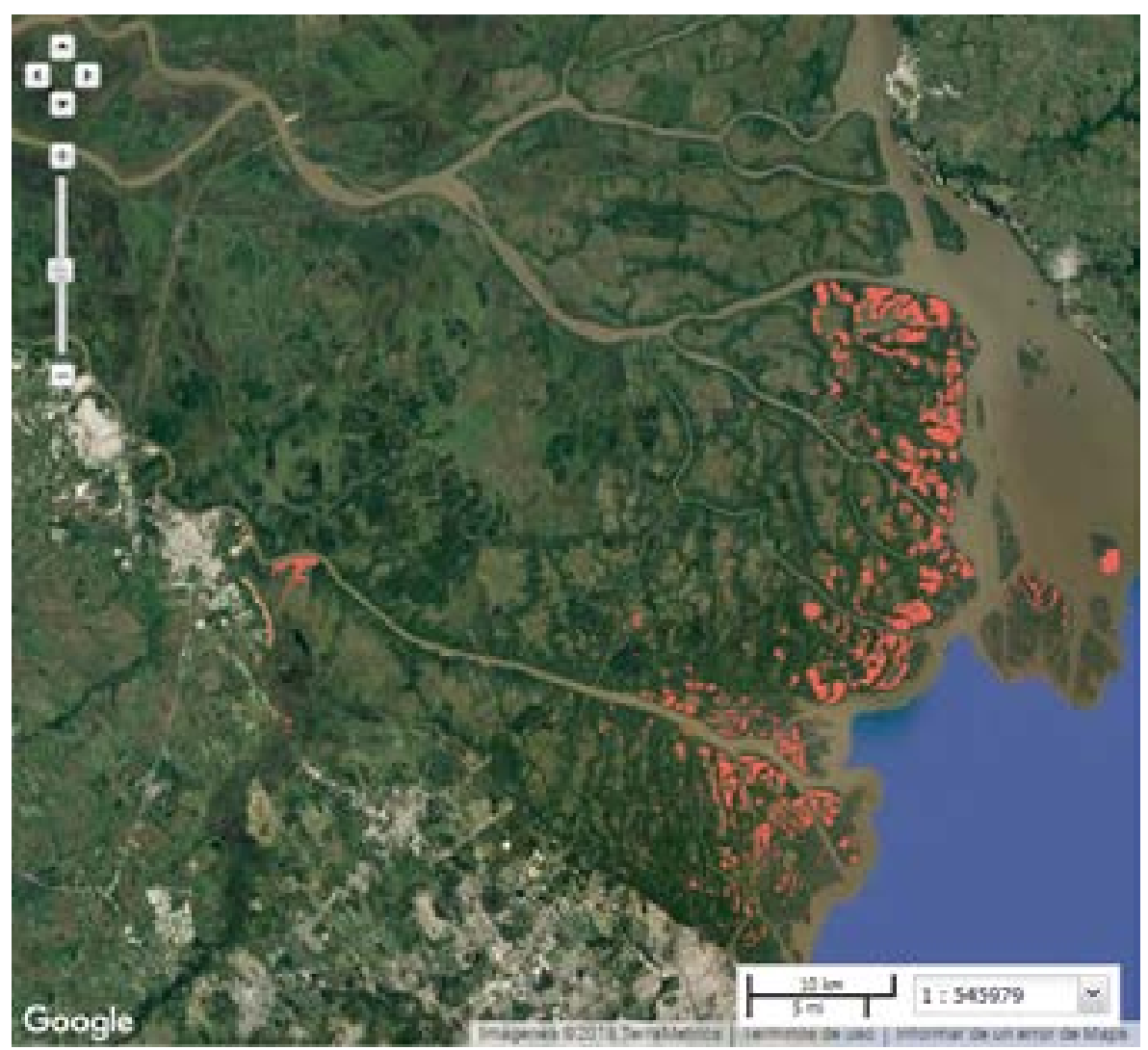

Figura 4. Segunda propuesta de ordenamiento territorial de los bosques nativos de la región "Talares de Barranca y Delta". Fuente: IDE Ambiental - Ministerio de Ambiente y Desarrollo Sustentable de la Nación (http://mapas.ambiente.gob.ar). 
nativo en todos esos lugares" y que "de hecho muchos de los lugares que ellos pensaban que eran ceibales [en realidad] eran forestaciones de sauce" (Carlos, miembro de una asociación de productores de la región, diciembre de 2016). Por medio de estos argumentos, los "isleños" resaltaban la necesidad de apelar a quienes conocían el territorio para definir cuáles eran y dónde estaban los "bosques nativos" del delta del Paraná. Es decir, poner "los pies en la tierra" no era solo un modo de confrontar con el uso de la interpretación de imágenes satelitales como forma de construcción del inventario, sino también de disputar la legitimidad de los asesores científicos en este proceso.

En esta fase, los "isleños" y los técnicos de las instituciones estatales de desarrollo rural y de promoción de la forestación se articularon estratégicamente con la autoridad de aplicación a fin de construir una nueva propuesta de OTBN. Uno de los técnicos de una institución de desarrollo rural que participó activamente en esta instancia recordó que

yo me puse en contacto con ellos [los técnicos de la autoridad provincial de aplicación], los cargué en la lancha y los llevé para que vean lo que tienen en la imagen. Como ellos veían en una imagen satelital, [queríamos] que tuvieran la referencia del terreno naturalmente cómo era. Entonces los llevé a ver, 'mirá, esto que ustedes marcaron como bosque nativo es esto'. Los llevé, les di una vuelta por el Delta donde me estaban esperando los productores de esas quintas, para mostrarles lo que ellos habían marcado como bosque nativo qué era realmente. (Guillermo, entrevista en noviembre de 2016)

Los técnicos de la autoridad de aplicación reconocieron que "corregimos y ajustamos [el mapa] cuando recorrimos junto con ellos", y señalaron que fueron los propios productores los que "propusieron que todos los relictos de bosques nativos que quedan fueran categorizados en la categoría de máxima conservación" (Juan María, Jorge, Agostina, Lara y Ana, entrevista grupal, abril de 2017). Uno de ellos sintetizó la importancia de esta articulación en otra ocasión previa, al señalar que por su intermedio "los productores del delta pasaron de ser los principales que estaban en contra de la ley o de nuestro mapa, a ser nuestros principales aliados" (Julia, Claudia, Ángela y Jorge, entrevista grupal, diciembre de 2016). La apertura de diferentes mecanismos políticos e institucionales facilitó la ocurrencia de esta articulación, a diferencia de lo ocurrido en otras regiones del país, donde el proceso incluyó exclusiones deliberadas a ciertos agentes (Schmidt, 2014; Vera, 2015).

Las dos propuestas de OTBN eran radicalmente diferentes: si bien todos los relictos relevados en la región ahora eran categorizados con el máximo nivel de conservación (esto es, en color rojo), se había producido una reducción del $80 \%$ de la superficie inventariada (figura 4). Los asesores científicos que habían participado en la construcción de la primera propuesta manifestaron públicamente su rechazo a estos cambios, especialmente en zonas asociadas a emprendimientos inmobiliarios. Sin embargo, sus demandas no fueron atendidas y la autoridad de aplicación decidió presentar formalmente la nueva propuesta en una segunda audiencia pública en febrero de 2014.

En esta nueva audiencia pública, el 70\% de los oradores estaban vinculados al conflicto en Quilmes-Avellaneda y se manifestaron en contra del OTBN propuesto para la provincia por considerar que beneficiaba a los desarrolladores inmobiliarios. Por su parte, solo el $12 \%$ de los oradores estaban relacionados con el delta bonaerense (y más específicamente con la Zona Núcleo Forestal), pero todos se expresaron a favor de la propuesta: productores familiares 
capitalizados, productores familiares empresariales, representantes de empresas forestoindustriales y técnicos de las agencias estatales que operan en territorio. Centrándonos en la Región Delta, el OTBN producido había sido el resultado del proceso de articulación entre los "isleños" más capitalizados, los técnicos de instituciones estatales vinculados a la forestación y los técnicos de la autoridad de aplicación de la "Ley de Bosques". En palabras de los técnicos de la institución estatal de desarrollo rural, "la autoridad de aplicación había entendido cómo era la mano, los productores estaban de acuerdo con el mapa, los organismos oficiales estaban de acuerdo con el mapa", y por lo tanto "el mapa ya está consensuado" (Guillermo, entrevista en noviembre de 2016).

Un punto de vista similar esbozó un funcionario de la autoridad de aplicación, según quien la región Delta y Talares de Barranca "fue la zona donde mejor se logró reunir a los actores y consensuar cómo hacer el mapa [...] [fue] la que más convocatoria tuvo y donde se llegó a un acuerdo total, por lo menos con los representantes más visibles" (Juan María, Jorge, Agostina, Lara y Ana, entrevista grupal, abril de 2017). Esto representa una diferencia radical respecto de los procesos de producción del OTBN en otras provincias, atravesados por el enfrentamiento público y el conflicto abierto entre las partes intervinientes, como lo atestiguan los casos de Salta (Schmidt, 2014) y Córdoba (Silvetti et al. 2013; Vera, 2015), entre otros.

Como hemos señalado al inicio de este artículo, los agentes sociales vinculados con la actividad forestal demandaban la construcción de un OTBN que les permitiera continuar con ella. Dado que el ordenamiento final propuesto satisfacía esta demanda, hacia fines del año 2014, sus preocupaciones se centraban en la necesidad de que fuera sancionado por el Poder Legislativo de la provincia. Al decir de los técnicos de la autoridad nacional de aplicación entrevistados, "antes, la queja de los productores forestales era 'todo está rojo', hoy en día es 'falta [la aprobación d]el ordenamiento'" (Julia, Claudia, Ángela y Jorge, entrevista grupal, diciembre de 2016). Finalmente, en agosto de 2015, el anteproyecto de "Ley de Bosques" ingresó formalmente a la Cámara de Senadores de la provincia de Buenos Aires para su tratamiento legislativo, que finalizó con la sanción de la Ley Provincial 14.888 en diciembre de 2016.

\section{A modo de cierre}

En este artículo analizamos los modos en que se produjo la articulación del colectivo de identificación "isleños" en el proceso de producción del ordenamiento territorial de los bosques nativos del delta bonaerense del río Paraná realizado en el marco de la "Ley de Bosques". Si el espacio estatal debe ser abordado como un campo de lucha, toda política pública está necesariamente en continua redefinición como efecto de las disputas que están en permanente (re)producción (Cowan Ros, 2016).

En este caso, la articulación de un colectivo de identificación "isleño" (cuyas prácticas de vida y la permanencia en "la isla" se veían amenazadas, según los agentes sociales vinculados con la actividad forestal) fue central para comprender el proceso de producción de la política bajo análisis. De tal modo, el OTBN no puede ser pensado como un mero producto del accionar de una institución estatal ni del enfrentamiento entre agentes estatales y no estatales. Contrariamente, el OTBN es el resultado de las disputas y negociaciones entre agentes estatales y no estatales que, por medio de articulaciones contingentes, 
buscan acceder y dominar los espacios de toma de decisión en pos de sus intereses específicos.

En un artículo posterior será necesario complementar este estudio y analizar las formas de articulación del colectivo "isleños" en la aprobación de la "Ley de Bosques", ya en la órbita del Poder Legislativo de la provincia (2015-2016) (figura 2). Eso permitirá evidenciar, entre otras cosas, que el direccionamiento de esta política pública no se vio sustantivamente afectado por los cambios en el signo partidario de las coaliciones gobernantes tanto a nivel nacional como provincial, y reforzar el argumento de que las demandas del colectivo "isleño" continúan articulándose en torno al mismo eje de confrontación y la misma activación de la adscripción identitaria en todo el proceso de institucionalización de la ley.

Por otra parte, los estudios etnográficos sobre la producción de políticas ambientales son socialmente relevantes: dado que la "Ley de Bosques" demanda que las provincias lleven adelante procesos de actualización del OTBN cada cinco años, estos estudios también pueden contribuir a reconfigurar los (futuros) procesos de inclusión/exclusión que se producen en estas disputas (Stecher, 2013). La situación de la Ley de Bosques en la provincia de Córdoba, en ese sentido, ofrece una primera aproximación al carácter conflictivo de los procesos de actualización en el marco de esta ley (Koberwein, 2018), y la articulación de los estudios realizados en los diferentes momentos -como Silveti et al. (2013), Vera (2015) y Koberwein (2018)- permite comprender más cabalmente estos procesos. Simultáneamente, como lo plantean Aguiar, Mastrángelo, García Collazo, Camba Sans, Mosso et al. (2018) en el análisis realizado en la Región Chaqueña, reflexionar críticamente sobre lo ocurrido es fundamental para la producción de propuestas que mejoren el desempeño de la ley y favorezcan la articulación investigación-gestión.

El estudio de caso también pone de manifiesto la expresión de sensibilidades territoriales al interior de las instituciones estatales (Oszlak, 2006). En este caso, ciertas zonas habían sido concebidas como áreas forestales desde agencias estatales específicas, y por tanto eran parte de su 'ámbito funcional': a partir de esa premisa, la injerencia de una nueva agencia estatal con objetivos disímiles podía ser interpretada como amenazante por los técnicos y funcionarios. De hecho, en la informalidad de la conversación casual, varios técnicos refirieron a los "enfrentamientos" entre ellas y "las luchas cuerpo a cuerpo" existentes en los primeros años (Registro de campo, noviembre y diciembre de 2016). Así, la práctica etnográfica deviene una herramienta fundamental para comprender estos procesos, así como los modos en que operan los street-level bureaucrats en la producción de las políticas públicas (Lipsky, 1996). Al mismo tiempo, el estudio de caso permite evidenciar las formas en que se expresan sus contradicciones de manera situada (Arzeno y Ponce, 2013).

Finalmente, cabe señalar que los procesos históricos y políticos de identificación, siempre contingentes, son constitutivos en la configuración de dispositivos culturales y políticos relevantes (Grimson, 2011). Sin embargo, la existencia de un marco de referencia compartido por un colectivo no supone que este sea homogéneo. Por lo tanto, los estudios etnográficos permiten comprender las formas en que las identidades territoriales y sus heterogeneidades constitutivas (como la identidad "isleña") son activadas políticamente en contextos sociohistóricos específicos (Isla, 2003). Pero, además, permiten comprender cómo estas activaciones son recreadas por otros agentes sociales (como los técnicos de las diferentes agencias estatales), y cómo contribuyen a configurar 
las confrontaciones territoriales en términos tales que les permiten a los diferentes agentes mejorar sus posiciones en las disputas por la definición de las formas de uso y apropiación de los bosques y, más ampliamente, el ambiente en general (Straccia, 2019).

\section{Financiamiento}

Esta investigación fue realizada en el marco de dos proyectos UBACyT financiados por la Universidad de Buenos Aires en los períodos 2014-2017 (20020130100147BA) y 20182020 (20020170100492BA). Complementariamente, las instancias de trabajo de campo fueron financiadas por el Consejo Nacional de Investigaciones Científicas y Técnicas a través de un Proyecto PIP 2015-2017. Este documento es resultado del financiamiento otorgado por el Estado Nacional, por lo tanto queda sujeto al cumplimiento de la Ley $N^{\circ}$ 26.899 .

\section{Agradecimientos}

Agradezco a la UBA y al CONICET por el financiamiento otorgado, sin el cual no hubiera podido llevar adelante esta investigación. También debo agradecer a la Dra. Cynthia Pizarro por sus valiosos comentarios, fundamentales para la producción de este artículo, y a todos los/as entrevistados/as que nos abrieron sus puertas, sus memorias y sus historias. Finalmente, mi agradecimiento también a los dos revisores anónimos, cuyos aportes contribuyeron sustancialmente a mejorar la claridad y calidad del artículo.

\section{Biografía}

Magíster en Políticas Ambientales y Territoriales (FFyL-UBA), actualmente se encuentra cursando el Doctorado en Ciencias Sociales en la Facultad de Ciencias Sociales (UBA). Es becario doctoral del CONICET y ayudante primero en la Cátedra de Extensión y Sociología Rurales (FA-UBA). 


\section{Q Referencias bibliográficas}

» Abrams, P. (1988) Notes on the difficulty of studying the State. Journal of Historical Sociology 1(1), 58-89.

» Aguiar, S., Mastrángelo, M., García Collazo, M. A., Camba Sans, G., Mosso, C., Ciuffoli, L., Schmidt, M., Vallejos, M., Langbehn, L., Cáceres, D. Merlinsky, G., Paruelo J., Seghezo, L., Staiano, L., Texeira, M., Volante, J. y Verón, S. (2018). ¿Cuál es la situación de la Ley de Bosques en la Región Chaqueña a diez años de su sanción? Revisar su pasado para discutir su futuro. Ecología Austral 28, 400-417.

»Alonso, A. y Costa, V. (2002) Por uma sociologia dos conflitos ambientais no Brasil. En H. Alimonda (Ed.), Ecología política. Naturaleza, sociedad y utopía (pp. 115-137). Buenos Aires: CLACSO.

»Althabe, G. y Hernández, V. (2004) Implicación y reflexividad en antropología. Journal des Anthropologues 98-99, 15-36.

»Arzeno, M. y Ponce, M. (2013) El rol del Estado y las políticas públicas de „desarrollo“ en Misiones. Contradicciones emergentes con relación a la agricultura familiar. En M. Manzanal y M. Ponce (comps.), La desigualdad ¿del desarrollo?: controversias y disyuntivas del desarrollo rural en el norte argentino (pp. 69-102). Buenos Aires: Fundación CICCUS.

" Astelarra, S. (2018) La memoria del agua: el agua es río y el río es memoria. Estudios del Hábitat 16 (2), e045.

»Astelarra, S. y Domínguez, D. (2015) Los junqueros de las islas del Delta del Paraná: sujetos emergentes en un territorio amenazado. Estudios Socioterritoriales. Revista de Geografía 17 (ene-jun), 129-162.

» Balbi, F. A. (2012) La integración dinámica de las perspectivas nativas en la investigación etnográfica. Intersecciones en Antropología 13, 485-499.

» Balbi, F. A. y Boivin, M. (2008) La perspectiva etnográfica en los estudios sobre política, Estado y gobierno. Cuadernos de Antropología Social 28, 7-17.

"Blanco, D. y Méndez, F. (Comps.) (2010) Endicamientos y terraplenes en el Delta del Paraná: situación, efectos ambientales y marco jurídico. Buenos Aires: Fundación para la Conservación y el Uso Sustentable de los Humedales / Wetlands International.

» Blaser, M. (2009) La ontología política de un programa de caza sustentable. Red de Antropologías del Mundo 4, 81-108.

»Brosius, J. P. (1997) Endangered forest, endangered people: environmentalist representation of indigenous knowledge. Human Ecology 25, 47-69.

»Brosius, J. P. (1999) Analyses and interventions: anthropological engagements with environmentalism. Current Anthropology 40, 277-310.

» Bryant, R. (2000) Politicized moral geographies. Debating biodiversity conservation and ancestral domain in the Philippines. Political Geography 19, 673-705.

" Bryant, R. y Bailey, S. (1997) Third world political ecology. UK: Routledge, Taylor \& Francis e-Library.

"Calefato, N. (2018) Transformaciones ambientales e (in)justicia espacial: el caso de la ribera de Quilmes y Avellaneda (tesis de grado). Facultad de Agronomía, Universidad de Buenos Aires, Argentina. 
" Cowan Ros, C. (2016) Estatalidades politicas publicas y movimientos sociales en su configuración interdependiente. Una perspectiva analítica. Working Paper Series Contested_Cities, WPCC-160007

"Das, V y Poole, D. (2008) El Estado y sus márgenes. Etnografías comparadas. Cuadernos de Antropología Social 27, 19-52.

"Esain, J. A. (2004) El federalismo ambiental. Reparto de competencias legislativas en materia ambiental en la Constitución Nacional y la Ley General del Ambiente 25.675. Jurisprudencia Argentina, 2004-I-776.

"Escobar, A. (2000) El lugar de la naturaleza y la naturaleza del lugar: ¿globalización o postdesarrollo? En E. Lander (Ed.), La colonialidad del saber: eurocentrismo y ciencias sociales. Perspectivas Latinoamericanas (pp. 113-143). Buenos Aires: CLACSO.

》Espósito, G. (2012) La polis colla. Tierra, cultura y política en la Quebrada de Humahuaca, Jujuy. Nuevo Mundo, Mundos Nuevos - EHESS, 11.

" Feito, M. C. (2005) Antropología y desarrollo rural. Contribuciones del abordaje etnográfico a los procesos de producción e implementación de políticas. Avá 6, 1-26.

"Fernández, S. (2016) La política forestal en Argentina y su contribución a las transformaciones en el Delta del Paraná (tesis de grado). Facultad de Agronomía, Universidad de Buenos Aires, Argentina.

"Ferrero, B. (2005) „La ecología“ de los colonos. Búsquedas de inclusión en un territorio ambientalista. Anuario de Estudios en Antropología Social 2005, 187-197.

" Foladori, G y Taks, J. (2004) Um olhar antropológico sobre a questao ambiental. MANA 10(2), 323-348.

» Galafassi, G. (2004) Colonización y conformación moderna de las tierras del Delta del Paraná, Argentina (1860-1940). Revista Complutense de Historia de América 30, 111-130.

"Galafassi, G. (2005) La pampeanización del Delta: sociología e historia del proceso de transformación productiva, social y ambiental del Bajo Delta del Paraná. Buenos Aires, Argentina: Ed. Extramuros.

" Grimson, A. (2011) Los límites de la cultura. Crítica de las teorías de la identidad. Buenos Aires, Argentina: Siglo XXI Editores.

" Guber, R. (2001) La etnografía. Método, campo y reflexividad. Buenos Aires: Ed. Norma.

" Gutiérrez, R. (2017) La confrontación de coaliciones sociedad-estado: la política de protección de bosques nativos en Argentina (2004-2015). Revista SAAP 11(2), 283-312.

» Haesbaert, R. (1999) Identidades Territoriais. En Z. Rodendahl y R. Lobato Correa, Manifestações culturais no espaço. Río de Janeiro: EDUERJ.

" Hale, C. (2006) Activist research v Cultural critique. Indigenous land rights and the contradictions of politically engaged anthropology. Cultural Anthropology 21(1), 96-120.

" Hall, S. (2003) Introducción: ¿quién necesita 'identidad'? En S. Hall y P. Du Gay, Cuestiones de identidad cultural (pp. 13-39). Buenos Aires: Amorrortu Editores.

》 Hammersley, M. y Atkinson, P. (2007) Ethnography: principles in practice. UK: Taylor \& Francis e-Library.

"Isla, A. (2003) Los usos políticos de la memoria y la identidad. Estudios Atacameños 26, $35-44$.

》 Koberwein, A. (2018) Ciencia, derecho, política y cultura en el conflicto por el bosque nativo en la provincia de Córdoba, Argentina. Revista del Museo de Antropología 11(1), 217-228. 
»Koopmans, R. y Statham, P. (2000) Challenging Immigration and Ethnic Relations Politics. Comparative European Perspectives. Oxford: Oxford University Press.

»Laclau, E. y Mouffe, C. (1987) Hegemonía y estrategia socialista. Hacia una radicalización de la democracia. Madrid: Siglo XXI Editores.

» Lipsky, M. (1996) Los empleados de base en la elaboración de políticas públicas. En J. Brugué y J. Subirats (eds.), Lecturas de Gestión Pública (pp. 279-298). Madrid, España: INAP.

» Little, P. E. (2007) Political ecology as ethnography: a theoretical and methodological guide. Horizontes Antropológicos 3, 1-16.

» Ministerio de Ambiente y Desarrollo Sustentable de la Nación (MAyDS). (2016) Ley $N^{\circ}$ 26331 de presupuestos mínimos de protección ambiental de los bosques nativos: informe de estado de implementación 2010-2015. Ministerio de Ambiente y Desarrollo Sustentable de la Nación, Argentina.

» Melé, P. (2003) Introduction: conflits, territoires et action publique. En P. Melé, C. Larrue y M. Rosemberg, Conflits et territoires (pp. 13-32). Francia: Presses Universitaires Francois-Rabelais.

» Melucci, A. (2004) The process of collective identity. En H. Johnston y B. Klandermans, Social movements and culture (pp. 41-63). Minnesota: University of Minnesota Press.

» Moreira, C. J. (2018) La institucionalización del desarrollo rural en los procesos de innovación tecnológica de manejo del agua en la Zona Núcleo Forestal del Delta del Paraná (tesis de maestría). FLACSO, Argentina.

» Noel, G. (2013) De los Códigos a los Repertorios: algunos atavismos persistentes acerca de la cultura y una propuesta de reformulación. Revista Latinoamericana de Metodología de las Ciencias Sociales 3(2), 1-31.

» Nygren, A. (1999) Local knowledge in the environment-development discourse: from dichotomies to situated knowledges. Critique of Anthropology 19, 267-288.

»Olemberg, D. (2015) Formas actuales de la organización social de la producción forestal en el Bajo Delta del río Paraná (tesis doctoral). Facultad de Ciencias Agropecuarias, Universidad Nacional de Córdoba, Argentina.

»Organismo Provincial para el Desarrollo Sostenible (OPDS). (2011a) Acta Audiencia Pública Ambiental - 19 de Abril de 2011. Organismo Provincial para el Desarrollo Sostenible, Gobierno de la Provincia de Buenos Aires, Argentina

» Organismo Provincial para el Desarrollo Sostenible (OPDS). (2011b) Taller participativo de información y consulta sobre el Ordenamiento Territorial de los Bosques Nativos de la Provincia de Buenos Aires. Organismo Provincial para el Desarrollo Sostenible, Gobierno de la Provincia de Buenos Aires, Argentina.

» Organismo Provincial para el Desarrollo Sostenible (OPDS). (2013) Informe de las actuaciones desarrolladas por el Organismo Provincial para el Desarrollo Sostenible (OPDS) en el marco de la Ley Nacional 26331 de Presupuestos Mínimos de Protección Ambiental de los Bosques Nativos. Organismo Provincial para el Desarrollo Sostenible, Gobierno de la Provincia de Buenos Aires, Argentina

» Opotow, S. y Weiss L. (2000) Denial and the process of moral exclusion in environmental conflict. Journal of Social Issues 56(3), 475-490.

» Oszlak, O. (2006) Burocracia estatal: política y políticas públicas. POSTData Revista de Reflexión y Análisis Político 11(4), 1-30.

»Penalva Verdú, C., Alaminos Chica, A., Francés García, F. J. y Santacreu Fernández, Ó. A. (2015) La investigación cualitativa: técnicas de investigación y análisis con Atlas.Ti. Cuenca: PYDLOS Ediciones. 
" Piermattei, S. (2013) Local farmers vs environmental universalism: Conflicts over nature conservation in the Parco Nazionale dei Monte Sibillini, Italy. Journal of Political Ecology 20, 306-317.

"Pizarro, C. (2006) Tras las huellas de la identidad en los relatos locales sobre el pasado. Cuadernos de Antropología Social 24, 113-130.

"Pizarro, C. (2016) Trabajadores paraguayos en la producción forestal del Delta Inferior del río Paraná. En S. Aparicio y R. Benencia (comps.), De migrantes y asentados. Trabajo estacional en el agro argentino (pp. 115-138). Buenos Aires: Fundación CICCUS.

》Pizarro, C (Ed.). (2019) „Nosotros creamos el Delta“. Habitar, forestar y conservar un humedal. Buenos Aires: Fundación CICCUS.

"Pizarro, C., Ciccale Smit, M. y Moreira, C. J. (2018) "Vino la marea y nos dejó en la vía". Experiencias de las inundaciones de productores forestales en un área del Delta Inferior del río Paraná. En R. Benencia y C. Pizarro (comps.), Ruralidades, actividades económicas y mercados de trabajo en el Delta vecino a la Región Metropolitana de Buenos Aires (pp. 25-46). Buenos Aires: Fundación CICCUS.

»Pizarro, C. y Straccia, P. (2018) „Isleños“ y „ambientalistas“. Confrontaciones sobre la sustentabilidad de la producción forestal en los humedales del Delta del Paraná (20122013). En R. Benencia y C. Pizarro, Ruralidades, actividades económicas y mercados de trabajo en el Delta vecino a la Región Metropolitana de Buenos Aires (pp. 75-96). Buenos Aires: Fundación CICCUS.

"Quintana, R.D. y Bó, R. (2011) ¿Por qué el Delta del Paraná es una región única en la Argentina? En R.D. Quintana, M.V. Villar, E. Astrada, P. Saccone y S. Malzof, El Patrimonio natural y cultural del Bajo Delta Insular. Bases para su conservación y uso sustentable (pp. 43-54). Buenos Aires: Aprendelta.

"Sabatier, P. (1991) Toward Better Theories of the Policy Process. Policy Science \& Politics 24(2), 147-156.

"Santy, V. (2014) Nueva Costa del Plata: las formas de la legitimación y la resistencia en un conflicto socio-ambiental del sur del Conurbano bonaerense (tesis de maestría). FLACSO, Argentina.

"Schmidt, M. (2014) „Ordenadores y ordenados“. Actores en disputa en el ordenamiento territorial de bosques nativos en la provincia de Salta. Cuadernos de Antropología 11, 37-55.

》Shore, C. (2010) La antropología y el estudio de la política pública. Reflexiones sobre la ,formulación“ de las políticas. Antípoda. Revista de Antropología y Arqueología 10(enejun), 21-49.

" Shore, C. y Wright, S. (1997) Anthropology of Policy. Critical perspectives on governance and power. London: Routledge.

" Silvetti, F., Soto, G., Cáceres, D. y Cabrol, D. (2013) ¿Por qué la legislación no protege los bosques nativos de Argentina? Conflictos socioambientales y políticas públicas Mundo Agrario 13(26), 1-21.

"Skill, K. (2010) Investigar problemas ambientales en antropología social. Pertinencia social y científica: una aproximación al campo. Avá 18, 77-92.

»Stecher, G. (2013) Ley de Bosques. Su aplicación en territorios de comunidades campesinas e indígenas en la Provincia de Neuquén. Nuevos modos de exclusión. En VII Jornadas Santiago Wallace de Investigación en Antropología Social. ICA - FFyL - UBA.

"Straccia, P. (2019) „Esto lo tenemos que solucionar desde adentro“. El uso político de la identidad ,isleña en un área del Delta del río Paraná en los procesos de institucionalización de leyes ambientales (tesis de maestría). FFyL-UBA, Argentina. 
»Straccia, P., Monkes, J. y Cowan Ros, C. (2019) La producción de políticas preservacionistas. Disputas en la Zona Núcleo Forestal (Delta Inferior del río Paraná) en torno al proyecto de “Ley de Humedales”. En C. Pizarro (Ed.), „Nosotros creamos el Delta“. Habitar, forestar y conservar un humedal. Buenos Aires: Fundación CICCUS.

»Straccia, P. y Pizarro, C. (2019) Ecología política: aportes de la sociología y de la antropología. Cuadernos de Desarrollo Rural 16(84), 1-18. doi: https://doi.org/10.11144/Javeriana. cdr16-84.epas.

"Sundberg, J. (2004) Identities in the making: conservation, gender and race in the Maya Biosphere Reserve, Guatemala. Gender, Place \& Culture 11(1), 43-66.

» Taylor, S. y Bogdan, R. (1996) Introducción a los métodos cualitativos de investigación. Buenos Aires, Argentina: Editorial Paidós.

» Tsing, A. L. (2005) An etnography of global connection. USA: Princeton University Press.

»Vera, A. (2015) El primer ordenamiento territorial de bosques nativos de Córdoba: Algunos aspectos políticos e institucionales del proceso participativo. En M. Julia (Ed.), “La investigación jurídica en políticas públicas ambientales. Parte II” (pp. 211-231). Córdoba: Advocatus.

»Wedel, J., Shore, C., Feldman, G. y Lathrop, S. (2005) Toward an anthropology of public policy. Annals of the American Academy of Political and Social Science 600, 30-51.

» West, P., Igoe, J. y Brockington, D. (2006) Parks and peoples: the social impact of protected areas. Annual Review of Anthropology 35, 251-277. 